\title{
CLINICAL YEAR IN REVIEW
}

\section{Nonsmall cell lung cancer}

\author{
Jean-Paul Sculier
}

\begin{abstract}
The objective of this review is to report the Clinical Year in Review proceedings in the field of nonsmall cell lung cancer that were presented at the 2012 European Respiratory Society Congress in Vienna, Austria. Various topics were reviewed, including epidemiology, screening, diagnosis, treatment, prognosis, and palliative and end of life care.
\end{abstract}

KEYWORDS: Chemotherapy, epidemiology, lung cancer, screening, thoracic surgery, tyrosine kinase inhibitor

$\mathbf{T}$ he present article reports on the progress within the field of nonsmall cell lung cancer that was presented during the Clinical Year in Review session that took place at the 2012 European Respiratory Society (ERS) Congress in Vienna, Austria. The purpose of the session was to report the key messages of the most significant publications in this field in 2011 and 2012.

\section{EPIDEMIOLOGY}

A study on cancer mortality in the countries of the European Union predicted that, compared to 2007, in 2012 mortality from lung cancer will decrease by $10 \%$ in males (while remaining the leading cause of death by cancer) but increase by $7 \%$ in females (thus becoming the second leading cause of cancer mortality) [1]. This change is explained by the measures taken to restrict the use of tobacco. Data from the USA showed a similar trend [2], reporting that between 1975 and 2000 , tobacco control measures led to the avoidance of lung cancer-related deaths in 550,000 males and 250,000 females. This improvement should not hide the fact that in the USA cancer remains a major public health problem and that the need to continue the fight against smoking is still present.

Occupational factors are also important according to a French case-control study [3], especially exposure to asbestos, polycyclic aromatic hydrocarbons, crystalline silica and diesel exhaust. In 2012, diesel exhaust was classified by the International Agency for Research against Cancer in Lyon, France, as a type 1 carcinogen (i.e. sufficient level of evidence). 2013 will be the European Year of Air and the ERS has published 10 principles for clean air, including "Citizens are entitled to clean air, just like clean water and safe food" [4]. Among these principles, it is required to take measures to combat external pollution emitted by diesel combustion.

\section{SCREENING}

Important results from US studies were published in 2011. On the one hand, the lung cancer section of the large randomised study Prostate, Lung, Colorectal and Ovarian Cancer Screening Trial (PLCO) showed that in a population of 154,901 participants, annual chest radiograph screening did not improve lung cancer mortality [5]. These results are in accordance with the results of the large randomised studies performed many decades ago that showed no benefit for screening with chest radiography. Data from the control arm of the PLCO study, however, have allowed for a predictive risk model to be developed and used to select subjects for screening [6]. On the other hand, the randomised National Lung Screening Trial (NLST) tested computed tomography (CT) versus radiography in 53,454 patients at high risk, and showed a benefit of annual screening with lowdose chest CT in terms of reducing lung cancer mortality [7]. In practice, compared to chest radiographs, 40 subjects need to be screened in order to diagnose one case of lung cancer and 265 subjects need to be screened in order to avoid one death from lung cancer.

One new screening method had a very important impact in the international media with the introduction of using sniffer dogs [8]. These specially trained dogs (fig. 1) are able to identify, with good accuracy, patients with lung cancer and differentiate it from other chronic pulmonary diseases (e.g. chronic obstructive pulmonary disease), food and tobacco. Sensitivity in the study was $71 \%$ and specificity was $93 \%$ [8]. Research is now focused on the identification of the molecular signature of the exhaled air that the dogs identify.
AFFILIATION

Université Libre de Bruxelles (ULB), Institut Jules Bordet, Service des Soins Intensifs et Urgences Oncologiques, Brussels, Belgium.

CORRESPONDENCE

J-P Sculier

Université Libre de Bruxelles (ULB) Institut Jules Bordet

1 rue Héger-Bordet

B-1000 Brussels

Belgium

E-mail: sculier@bordet.be

Received:

Nov 212012

Accepted after revision:

Dec 132012

\section{PROVENANCE}

Submitted article, peer reviewed. 

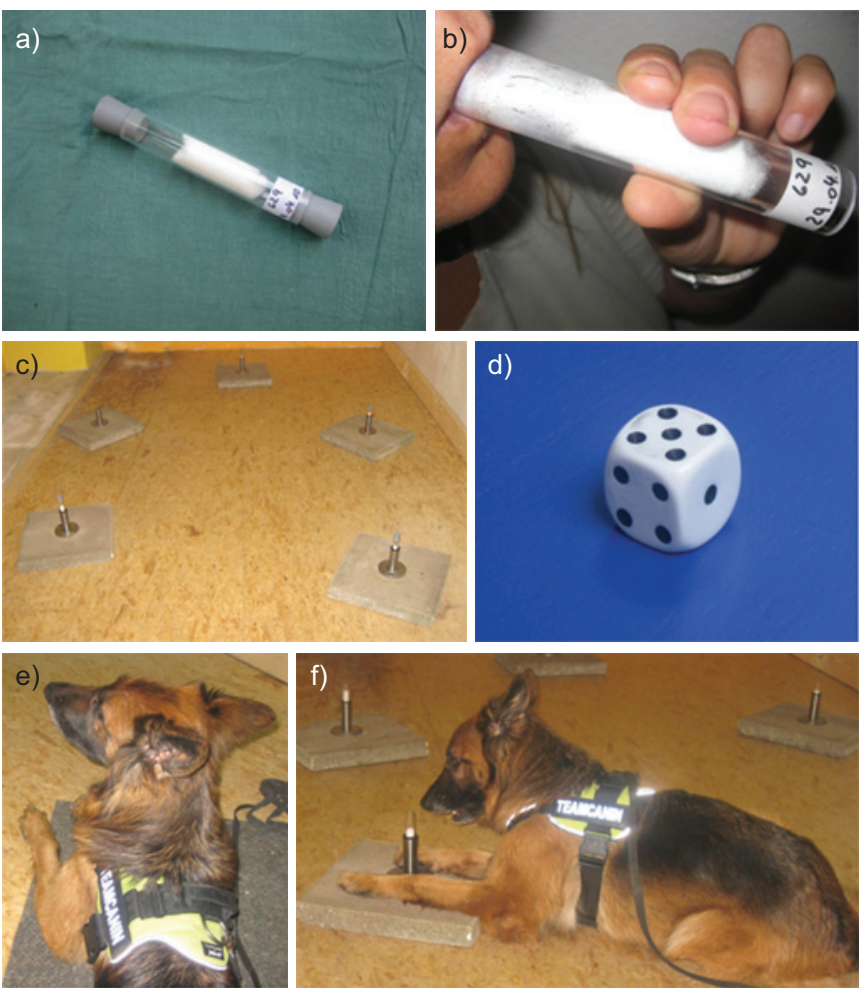

FIGURE 1. Applied methods for breath sampling and testing. a) Glass tube used for breath sampling. The lumen is filled with a polypropylene fleece. b) For breath sampling, study participants exhale through the collection device. c) Test set-up showing the probe retainers. d) The position of the lung cancer samples is randomised. e) Sniffer dogs are trained to identify lung cancer in the breath sample of patients. f) The dogs are trained to indicate a positive test tube by lying on the floor in front of the tube with their muzzle touching the test tube. Reproduced from [8] with permission from the publisher.

\section{DIAGNOSIS}

Diagnosis requires histological examination and determination of the extension of the tumour in order to determine the TNM stage. A Danish randomised study comparing staging with positron emission tomography (PET) combined with CT to classic invasive staging alone (mediastinoscopy and/or mediastinal lymph node biopsy with echo-endoscopy) showed the benefit provided by the PET-CT for $\mathrm{N}$ stage diagnosis [9]. Considering the risk of false-positive results, any positive node on the PET-CT must be sampled, as confirmed by the analysis of a secondary objective from another randomised study [10].

According to the new International Association for the Study of Lung Cancer (IASLC)/American Thoracic Society (ATS)/ERS multidisciplinary classification (table 1) of lung adenocarcinoma [11], obtaining sufficient tissue material is necessary, especially when searching for genetic abnormalities (epidermal growth factor receptor (EGFR) mutations, echinoderm microtubuleassociated protein-like (EML) 4/anaplastic lymphoma kinase (Alk) translocations). A Canadian consensus based on a systematic review has been published on this subject [12].

\section{TREATMENT}

Based on a systematic review of the literature, the European Lung Cancer Working Party (ELCWP) has recently published
TABLE 12011 International Association for the Study of Lung Cancer/American Thoracic Society/ European Respiratory Society classification of lung adenocarcinoma in research specimens

\section{Pre-invasive lesions}

Atypical adenomatous hyperplasia

Adenocarcinoma in situ ( $\leqslant 3 \mathrm{~cm}$ formerly solitary BAC)

Non-mucinous

Mucinous

Mixed mucinous/nonmucinous

Minimally invasive adenocarcinoma ( $\leqslant 3 \mathrm{~cm}$ lepidic predominant tumour with $\leqslant 5 \mathrm{~mm}$ invasion)

Nonmucinous

Mucinous

Mixed mucinous/nonmucinous

Invasive adenocarcinoma

Lepidic predominant (formerly nonmucinous BAC pattern with $>5 \mathrm{~mm}$ invasion)

Acinar predominant

Papillary predominant

Micropapillary predominant

Solid predominant with mucin production

Variants of invasive adenocarcinoma

Invasive mucinous adenocarcinoma (including formerly mucinous BAC)

Colloid

Fetal (low and high grade)

Enteric

BAC: bronchoalveolar carcinoma. Reproduced from [11] with permission from the publisher

recommendations on surrogate end-points to assess the early treatment efficacy and, thus, to predict increased survival or cure in practice [13]. These effective surrogate end-points are: objective response, time to progression, duration of response, local control, down staging, pathological complete response, pathological TNM (after surgery) and some circulating markers.

\section{Surgery}

Several studies have compared sub-lobar resection to lobectomy. All of the studies are retrospective with indirect comparisons. In the largest study, performed on the American Surveillance Epidemiology and End Results (SEER) database, data from 14,473 patients with stage I tumour treated by anatomical segmentectomy or lobectomy were collected between 1998 and 2007 [14], the latter approach provides a statistically significant survival advantage at $5 \mathrm{yrs}$, even after adjustment for other prognostic factors including tumour size.

A randomised study compared surgery alone for stage IB/IIIA to induction chemotherapy with cisplatin and gemcitabine followed by surgery [15]. This trial, which registered 270 patients, was stopped early due to lack of recruitment. Nevertheless, the authors observed a statistically significant improvement in survival in stage IIB/IIIA by induction chemotherapy.

\section{Chemotherapy for advanced disease}

A multicentre Italian trial compared chemotherapy regimens with two (doublets) or three (triplets) cytotoxic agents and with 
or without cisplatin [16]. A total of 433 patients were randomised to receive gemcitabine/cisplatin, gemcitabine/vinorelbine, gemcitabine/ifosfamide/cisplatin or gemcitabine/ifosfamide/ vinorelbine. The study showed the superiority of survival if the patient was receiving cisplatin-based treatment. The use of a triplet did not provide additional benefit.

In a meta-analysis, the role of maintenance therapy with a single drug has been assessed [17]. 12 randomised studies were included in the study. The overall analysis showed a survival advantage with maintenance therapy. The studies were categorised into two groups: 1) continuation of a drug already used in the induction regimen (continuation maintenance); and 2) switch to a new drug that the patient has not yet received (switch maintenance). A survival advantage remained in the switch maintenance subgroup meta-analysis but not in the continuation maintenance subgroup. There was no difference according to the type of drug used for maintenance: cytostatic agent or targeted therapy.

\section{Tyrosine kinase inhibitors}

A significant advance in therapy, tyrosine kinase inhibitors (TKIs) are part of the basic treatment of nonsmall cell lung cancer (mainly adenocarcinomas) with activating mutation of the EGFR gene (targeted therapy). It should be noted that in this situation, chemotherapy and TKIs have no cross-resistance and administration of TKI has the same effect on overall survival whether administered as first-line or salvage treatment. A randomised study with gefitinib, the IRESSA Pan-Asia Study, showed that progression-free survival was higher in the case of treatment with gefitinib if the mutation was present (without impact on survival, probably because many patients initially treated with chemotherapy received TKI at progression), but that it was higher with chemotherapy if the mutation was absent [18]. For erlotinib, the other TKI marketed in Europe, randomised studies in patients with a tumour with an activating mutation also showed similar results, with improved progression-free survival if treatment was started with a TKI [19, 20]. In addition, there was no significant difference in overall survival if treatment was crossed-over with chemotherapy as shown in the EURTAC (European Tarceva versus Chemotherapy) study [19]. It remains to be seen which of these two molecules is better in a comparative trial.

By contrast, these drugs have no significant effect on tumours without mutation or when mutations are not searched for. New published randomised trials confirm this lack of indication as first-line therapy compared to chemotherapy in nonsmokers [21] or as maintenance therapy after four cycles of induction platinum-based chemotherapy [22].

A nomogram was developed on the basis of clinical data (histology and smoking) to predict, in non-Asian patients, response to TKI therapy and the presence of activating mutations [23]. This approach may be useful for patients for whom there is no adequate tissue to perform genetic analyses. Nevertheless, the search for mutations is crucial. It can be quickly performed routinely even in the case of paucicellular material, as reported in a study from the UK [24] of 755 samples where the prevalence of mutations was $13 \%$ and the rate of technical failure was $5.4 \%$.
Crizotinib is a new TKI that is active against the fusion protein induced by the translocation between the EML4 and Alk genes. This genetic defect, affecting about $5 \%$ of tumours [25], is considered exclusive of KRAS and EGFR mutations in lung adenocarcinoma; the absence of these three genetic abnormalities ("triple null") is of the most frequent genotype. In 2012, crizotinib received notice of registration by the European Medicines Agency (London, UK).

\section{Oligometastatic disease}

Oligometastatic tumours are usually tumours with a single metastasis that can be treated surgically as well as the primary tumour. The case of unique brain metastases has long been known. Adrenal metastases, if they are unique, can also be resected provided that the primary tumour is controlled. In a US retrospective study with 37 cases, a 5-yr survival of $34 \%$ was reported with adrenalectomy in case of single secondary lesion [26]. For other locations, a systematic review identified 62 cases in the literature treated by metastasectomy (hepatic, gastrointestinal, thyroid, bone, etc.) with a survival rate at 5 yrs of $50 \%$ [27]. This curative approach, although it can rarely be offered, should not be forgotten.

\section{PROGNOSIS}

Many studies of prognostic factors have been published. Particularly interesting is the report [28] of the prognostic value of the histological subtypes of new lung adenocarcinoma classification [29]. Pre-invasive lesions have the best prognosis. The lepidic-predominant subtype has a good prognosis while the solid with mucin predominance and the micropapillarypredominant subtypes have the worst prognosis.

\section{PALLIATIVE CARE AND END OF LIFE}

In the USA, a randomised study showed that the majority of patients with lung cancer at a metastatic stage had a poor perception of their prognosis and that the early introduction of palliative care would enhance the understanding of their situation and, thus, their decision about their future [30]. This approach also allows for better management in palliative care structures when the situation becomes terminal [31].

In some countries in Europe, palliative care is managed by general practitioners. In Belgium and the Netherlands [32], most patients spend their last year of life at home, where many die. A large majority of patients have problems with physical and psychological distress in later life. In addition, receiving a diagnosis of lung cancer is hard to live with. In Sweden, a diagnosis of lung cancer is associated with a 12-times increased risk of cardiovascular deaths within 1 week and suicide within 3 months following the diagnosis [33].

\section{CONCLUSION}

In conclusion: 1) an antismoking policy has resulted in a significant decrease in the rate of deaths by lung cancer in Europe; 2) for screening, chest CT scans detect significantly more cases of lung cancers than chest radiographs; 3) single agent switch maintenance chemotherapy is associated with a survival advantage; 4 ) in the case of active EGFR mutations in advanced nonsmall cell lung cancer (to be routinely searched), the therapeutic project should include TKI and chemotherapy sequentially as induction or salvage treatments, whatever the sequence (TKI followed by chemotherapy or vice versa); and 
5) more attention should be given to delivering the diagnosis to the patient and the introduction of palliative care.

\section{STATEMENT OF INTEREST}

None declared.

\section{REFERENCES}

1 Malvezzi M, Bertuccio P, Levi F, et al. European cancer mortality predictions for the year 2012. Ann Oncol 2012; 23: 1044-1052.

2 Moolgavkar SH, Holford TR, Levy DT, et al. Impact of reduced tobacco smoking on lung cancer mortality in the United States during 1975-2000. J Natl Cancer Inst 2012; 104: 541-548.

3 Wild P, Gonzalez M, Bourgkard E, et al. Occupational risk factors have to be considered in the definition of high-risk lung cancer populations. Br J Cancer 2012; 106: 1346-1352.

4 Brunekreef B, Annesi-Maesano I, Ayres JG, et al. Ten principles for clean air. Eur Respir J 2012; 39: 525-528.

5 Oken MM, Hocking WG, Kvale PA, et al. Screening by chest radiograph and lung cancer mortality: the Prostate, Lung, Colorectal, and Ovarian (PLCO) randomized trial. JAMA 2011; 306: 1865-1873.

6 Tammemagi CM, Pinsky PF, Caporaso NE, et al. Lung cancer risk prediction: Prostate, Lung, Colorectal And Ovarian Cancer Screening Trial models and validation. J Natl Cancer Inst 2011; 103: 1058-1068.

7 Aberle DR, Adams AM, Berg CD, et al. Reduced lung-cancer mortality with low-dose computed tomographic screening. N Engl J Med 2011; 365: 395-409.

8 Ehmann R, Boedeker E, Friedrich U, et al. Canine scent detection in the diagnosis of lung cancer: revisiting a puzzling phenomenon. Eur Respir J 2012; 39: 669-676.

9 Fischer BM, Mortensen J, Hansen $\mathrm{H}$, et al. Multimodality approach to mediastinal staging in non-small cell lung cancer. Faults and benefits of PET-CT: a randomised trial. Thorax 2011; 66: 294-300.

10 Darling GE, Maziak DE, Inculet RI, et al. Positron emission tomography-computed tomography compared with invasive mediastinal staging in non-small cell lung cancer: results of mediastinal staging in the early lung positron emission tomography trial. J Thorac Oncol 2011; 6: 1367-1372.

11 Travis WD, Brambilla E, van Schil $\mathrm{P}$, et al. Paradigm shift in lung cancer as defined in the new IASLC/ATS/ERS lung adenocarcinoma classification. Eur Respir J 2011; 38: 239-243.

12 Ellis PM, Blais N, Soulieres D, et al. A systematic review and Canadian consensus recommendations on the use of biomarkers in the treatment of non-small cell lung cancer. J Thorac Oncol 2011; 6: 1379-1391.

13 Berghmans T, Pasleau F, Paesmans M, et al. Surrogate markers predicting overall survival for lung cancer: ELCWP recommendations. Eur Respir J 2012; 39: 9-28.

14 Whitson BA, Groth SS, Andrade RS, et al. Survival after lobectomy versus segmentectomy for stage I non-small cell lung cancer: a population-based analysis. Ann Thorac Surg 2011; 92: 1943-1950.

15 Scagliotti GV, Pastorino U, Vansteenkiste JF, et al. Randomized phase III study of surgery alone or surgery plus preoperative cisplatin and gemcitabine in stages IB to IIIA non-small-cell lung cancer. J Clin Oncol 2012; 30: 172-178.

16 Boni $\mathrm{C}$, Tiseo $\mathrm{M}$, Boni $\mathrm{L}$, et al. Triplets versus doublets, with or without cisplatin, in the first-line treatment of stage IIIB-IV nonsmall cell lung cancer (NSCLC) patients: a multicenter randomised factorial trial (FAST). Br J Cancer 2012; 106: 658-665.

17 Behera M, Owonikoko TK, Chen Z, et al. Single agent maintenance therapy for advanced stage non-small cell lung cancer: a metaanalysis. Lung Cancer 2012; 77: 331-338.

18 Fukuoka M, Wu YL, Thongprasert S, et al. Biomarker analyses and final overall survival results from a phase III, randomized, open-label, first-line study of gefitinib versus carboplatin/paclitaxel in clinically selected patients with advanced non-small-cell lung cancer in Asia (IPASS). J Clin Oncol 2011; 29: 2866-2874.

19 Rosell R, Carcereny E, Gervais R, et al. Erlotinib versus standard chemotherapy as first-line treatment for European patients with advanced EGFR mutation-positive non-small-cell lung cancer (EURTAC): a multicentre, open-label, randomised phase 3 trial. Lancet Oncol 2012; 13: 239-246.

20 Zhou C, Wu YL, Chen G, et al. Erlotinib versus chemotherapy as first-line treatment for patients with advanced EGFR mutationpositive non-small-cell lung cancer (OPTIMAL, CTONG-0802): a multicentre, open-label, randomised, phase 3 study. Lancet Oncol 2011; 12: 735-742.

21 Han JY, Park K, Kim SW, et al. First-SIGNAL: first-line singleagent iressa versus gemcitabine and cisplatin trial in neversmokers with adenocarcinoma of the lung. J Clin Oncol 2012; 30: 1122-1128.

22 Gaafar RM, Surmont VF, Scagliotti GV, et al. A double-blind, randomised, placebo-controlled phase III intergroup study of gefitinib in patients with advanced NSCLC, non-progressing after first line platinum-based chemotherapy (EORTC 08021/ILCP 01/ 03). Eur J Cancer 2011; 47: 2331-2340.

23 Girard N, Sima CS, Jackman DM, et al. Nomogram to predict the presence of EGFR activating mutation in lung adenocarcinoma. Eur Respir J 2012; 39: 366-372.

24 Leary AF, Castro DG, Nicholson AG, et al. Establishing an EGFR mutation screening service for non-small cell lung cancer - sample quality criteria and candidate histological predictors. Eur J Cancer 2012; 48: 61-67.

25 Paik JH, Choi CM, Kim H, et al. Clinicopathologic implication of ALK rearrangement in surgically resected lung cancer: a proposal of diagnostic algorithm for ALK-rearranged adenocarcinoma. Lung Cancer 2012; 76: 403-409.

26 Raz DJ, Lanuti M, Gaissert HC, et al. Outcomes of patients with isolated adrenal metastasis from non-small cell lung carcinoma. Ann Thorac Surg 2011; 92: 1788-1792.

27 Salah S, Tanvetyanon T, Abbasi S. Metastatectomy for extracranial extra-adrenal non-small cell lung cancer solitary metastases: systematic review and analysis of reported cases. Lung Cancer 2012; 75: 9-14.

28 Russell PA, Wainer Z, Wright GM, et al. Does lung adenocarcinoma subtype predict patient survival? A clinicopathologic study based on the new International Association for the Study of Lung Cancer/American Thoracic Society/European Respiratory Society international multidisciplinary lung adenocarcinoma classification. J Thorac Oncol 2011; 6: 1496-1504.

29 Travis WD, Brambilla E, Noguchi M, et al. International Association for the Study of Lung Cancer/American Thoracic Society/European Respiratory Society international multidisciplinary classification of lung adenocarcinoma. J Thorac Oncol 2011; 6: 244-285.

30 Temel JS, Greer JA, Admane S, et al. Longitudinal perceptions of prognosis and goals of therapy in patients with metastatic nonsmall-cell lung cancer: results of a randomized study of early palliative care. J Clin Oncol 2011; 29: 2319-2326.

31 Greer JA, Pirl WF, Jackson VA, et al. Effect of early palliative care on chemotherapy use and end-of-life care in patients with metastatic non-small-cell lung cancer. J Clin Oncol 2012; 30: 394-400.

32 Meeussen K, Van den BL, Echteld MA, et al. End-of-Life care and circumstances of death in patients dying as a result of cancer in Belgium and the Netherlands: a retrospective comparative study. J Clin Oncol 2011; 29: 4327-4334.

33 Fang F, Fall K, Mittleman MA, et al. Suicide and cardiovascular death after a cancer diagnosis. N Engl J Med 2012; 366: 1310-1318. 